\title{
STRIVING TO INCLUDE THE EXCLUDED: A CASE STUDY OF A SPECIAL EDUCATION INITIATIVE IN RURAL HONDURAS
}

\author{
Amanda Ketner Weissman ${ }^{1}$ \\ University of Michigan, USA
}

\begin{abstract}
Despite the existence of national policies that allow students with disabilities to be taught in the general education setting in Honduras, there is a gap between policy and practice as students with disabilities experience worse learning outcomes than their peers. Previous work has shown that this is due in part to a lack of knowledge among general education teachers on how to work successfully with students with disabilities. This paper examines the effectiveness of an approach to address this in rural Honduras by providing professional development for fifteen in-service teachers in eight schools to impart techniques for working with 56 students with both learning and physical disabilities. Through a combination of surveys, interviews, and observations, results show benefits to the teachers' beliefs, content knowledge, and pedagogy for students with disabilities. This work leads to potential policy implications for the adoption of similar programs throughout Honduras and Central America.
\end{abstract}

Keywords: Honduras, Latin America, Students with Disabilities, Program Evaluation, Professional Development

\section{Introduction}

With the rise of the global human rights movement came the trend towards inclusive education. Inclusive education is theorized to perpetuate democratic ideals by providing opportunities to all, address aspects of poverty, reflect the general trend of the diversification of societies, protect the rights of minorities, and reduce social stigma. By creating an education system that fosters integration, the hope is that societies will also become inclusive (Opertti \& Belalcázar, 2008). While inclusive education refers to accessible education for any

${ }^{1}$ Correspondence: University of Michigan, School of Education, 610 E. University Ave., Ann Arbor, MI 48109, USA: Email: ketneram@umich.edu 
student excluded from the traditional educational system, this paper focuses specifically on education for students with disabilities.

Beginning in the 1980s, the inclusive education movement sought to facilitate the integration of students with disabilities into general education classrooms with accommodations instead of educating these students in separate classrooms or even separate schools (Opertti \& Belalcázar, 2008). This incited debate about whether students with disabilities are best served learning with their traditional peers or in separate classrooms with more focused resources (Connor \& Ferri, 2007). Disagreement occurs around cost, efficiency, quality, and effectiveness as well as the ability for students to have increased access to social capital, intellectual capital, citizenship, social justice, empowerment, and self-determination (Connor \& Ferri, 2007; Zigmond, Kloo, \& Volonino, 2009). Throughout the debate, one consistency has been the imperative to address each student individually in response to their unique educational, social, emotional, and physical needs.

The global emphasis on educating students with disabilities was realized when it was included in the Sustainable Development Agenda in 2015. Captured under Goal 4: Quality Education, Target 4.5 explicitly aims to, “...eliminate gender disparities in education and ensure equal access to all levels of education and vocational training for the vulnerable, including persons with disabilities, indigenous peoples and children in vulnerable situations" (UN, 2017).

As this inclusive model increased in popularity and a spectrum of accommodations developed, such providing students with differentiated learning materials, the topic of focus shifted from the general need for inclusive education to that of best practices and the role of the teacher (Opertti \& Belalcázar, 2008). As education systems moved into the implementation phase of these policies, disconnects were seen between the intention of the policies and the results at the student level. When studying this breakdown between policy and student outcomes, a case study provides the opportunity to delve into the sociocultural nuances that contribute to the issue and deeply examine how they can be addressed (HesseBiber \& Leavy, 2017). Honduras is an example of a country that has embraced inclusive policies at the national level yet still has less than half of its children with disabilities attending school (Republica de Honduras: Secretaría de Educación, 2008; UNICEF, 2011; Viveros, 2004).

In this paper, I identify reasons for this discrepancy in Honduras at the primary school level and study the impact of one approach taken to address this issue with professional development (PD) for in-service general education primary school teachers in rural Honduras. This dual-approach PD consisted of weekly individual teacher coaching and approximately semi-annual whole-group seminars with all teachers involved in the PD. I investigated whether teachers participating in the PD perceived it to be beneficial with respect to teaching their students with disabilities and why or why not. Overall, I found that teachers believed the PD both increased their knowledge of students with disabilities and enhanced their pedagogy.

My research seeks to begin filling the gap in the literature regarding approaches to improving the quality of education for students with disabilities in Honduras. By studying teachers of students with disabilities living in rural poverty, this paper both draws needed attention to a highly marginalized population that is often left out of the discourse surrounding Honduran education and discusses the effects of one approach to better serving these students (Shulman, 1997). Although there have been evaluations of educational interventions in other parts of Latin America and similar programs in the United States, there is a void of work studying the efficacy of PD programs for this population in Honduras 
(Anderson, 2005; Coombs-Richardson \& Mead, 2001; Knapp, 2003; Tatto, 1998; Waitoller \& Artiles, 2013).

\section{Inclusive Education in Honduras}

\section{Existing National Policies}

At the national level, Honduras has policies in place advocating for inclusivity both pertaining to general public life as well as to education specifically. Despite ratifying both the International Convention on the Laws of the Persons with Disability in 2006 and the InterAmerican Convention on the Elimination for All Forms of Discrimination Against Persons with Disabilities in 2011, Honduras is lacking regulations related to accessibility of public transportation and public housing for people with disabilities (International Disability Rights Monitor, 2004; National Federation of Organizations of Persons with Disabilities of Honduras, 2013; Organization of American States, 2011). National documents are not available in Braille, and several government buildings are not wheelchair-accessible. Similarly, there are no policies designed to help people with "speech or hearing impairments communicate with public officials in times of natural disasters, civil emergencies, or crime" according to the International Disability Rights Monitor (2004) (p. 243). One positive contrast to this lack of policies is the existence of a policy requiring businesses to maintain a quota of people with disabilities when hiring (Japan International Cooperation Agency, 2002). Overall, despite the signaling of good intentions by signing international accords, Honduras' policies are often problematic for people living with disabilities. This overall gap in inclusivity is particularly seen in education policies.

According to the country's constitution passed in 1982, basic education in Honduras was designed to be free, obligatory, secular, and democratic with the purpose of preparing students for a life of civic engagement. When the national curriculum was established in 1998, it emphasized that education should respect individuals' dignity and should be accessible to all students, regardless of socio-economic and ethnic background (UNESCO International Bureau of Education, 2010). Guadalupe (2007) noted that the Honduran curriculum and surrounding policies reflect the sentiment that, "all children, without exception, can learn and develop the necessary basic skills if they are offered quality education opportunities" and the need for "using multiple and differentiated strategies for working in the classroom" (p. 18). An example of a specific approach aimed at increasing access was the policy abolishing the use of entrance exams that were often used to exclude students with learning disabilities (Republica de Honduras: Secretaría de Educación, 2008). As Honduras evolved in the formation of its policies, the Secretary of Education collaborated with UNICEF to promote inclusive policies and institutional behavioral change (UNICEF, 2011).

Although the national curriculum took a human rights approach that respects diversity, it did not explicitly make provisions for students with disabilities (Republica de Honduras: Secretaría de Educación, 2008). Despite the passage of the Equity and Comprehensive Development for Persons with Disabilities Act in 2005, there are still gaps in policies. For example, there are no policies that make discrimination against students with disabilities illegal or that address the need for alternate assessments for such students. Likewise, there is a lack of policies providing teachers and schools with the necessary support, resources, and infrastructure to work with students with disabilities or policies aimed at incorporating families and communities in the process of inclusive education (Guadalupe, 2007). 


\section{Student Outcomes: Disconnect Between Policies and Practice}

Looking at the broader national context, Honduras is a country of high poverty, inequality, and deprivations. Although Honduras has made gains in life expectancy, average years of schooling, and GNI (Gross National Income) per capita since 1990 to the point where it is considered to have a medium HDI (Human Development Index) score, it is still below the average for its neighbors of El Salvador and Nicaragua, its region of Latin America and the Caribbean, and the other countries with medium HDI values. Furthermore, when the HDI is intersected with inequality, Honduras' score falls from 0.625 to 0.443 , revealing vast inequalities within the country (UNDP, 2016). When considering additional measures of development, the MPI (Multidimensional Poverty Index) reveals similar conclusions about inequalities in Honduras. With respect to poverty, $66.5 \%$ of the population lives below the national poverty line, and deprivations associated with poverty as disproportionately seen in rural areas. All of the indicators across the three dimensions of education, health, and living standards included in the composite MPI score are execrated in the rural areas, the most intense of which are those associated with living standards. Comparatively, of the four countries in Central America included in the MPI calculations, Honduras had the worst ranking (Oxford Poverty and Human Development Initiative, 2016). Honduras' poor HDI and MPI values depict a context in which students with disabilities struggle to find an appropriate education.

Amadio (2009) summarized the situation in Honduras when he described the gap between the spirit embodied in national policies and the national curriculum and the daily education experience of students with disabilities. Estimates for the percentage of the population that is disabled range from 10-14\% (International Disability Rights Monitor, 2004). One study found that the most common problems are with locomotion, vision, hearing, language, and mental delay and that $23 \%$ of the disabled population consists of minors under the age of 18 (National Federation of Organizations of Persons with Disabilities of Honduras, 2013).

By making education compulsory for only 6 years, Honduras is one of seven countries in Latin America and the Caribbean where secondary school is not required; therefore, this paper focuses mainly on primary education. Compared to the national net attendance rate for primary school of $93 \%$, estimates of the percentage of students with disabilities who attend school range from 20-57\% (UNESCO UIS, 2017; UNICEF, 2011; Viveros, 2004). Although obtaining reliable data of this sensitive nature is difficult, reports indicate there is a discrepancy and that students with disabilities are not attending school at the same rates as their peers (International Disability Rights Monitor, 2004). This is seen through the fact that $51 \%$ of the population with disabilities is illiterate compared to $19 \%$ of the general population (Viveros, 2004).

This incongruity is exacerbated by the fact that $82 \%$ of people with disabilities in Honduras live in poverty; of the children with disabilities, $67 \%$ live in poverty while $80 \%$ live in rural settings (Japan International Cooperation Agency, 2002; Viveros, 2004). These data are significant because school attendance rates are associated with both rurality and income level (Guadalupe, 2007; Solís \& Godoy, 2010). Likewise, in the country identified as the third poorest in the Americas and with the most extreme differences in income between the wealthiest and poorest quintile in the region, income is unsurprisingly associated with years of education (International Disability Rights Monitor, 2004; Solís \& Godoy, 2010).

To help educate the students with disabilities too extreme to be accommodated in a general education classroom, Honduras established 46 special education centers in the country. However, most of these are located in the two most populous cities - Tegucigalpa 
and San Pedro Sula - and have to be heavily subsidized by NGOs because the government funding is insufficient (National Federation of Organizations of Persons with Disabilities of Honduras, 2013; Richler, 2004; UNESCO International Bureau of Education, 2010). One study found that only $4 \%$ of students with disabilities attend such centers (International Disability Rights Monitor, 2004). If the outlook for obtaining education for students with disabilities was not bleak enough, studies have shown that quality of instruction received by students included in the general education classroom is poor (National Federation of Organizations of Persons with Disabilities of Honduras, 2013).

\section{Literature Review}

\section{Reasons for the Disconnect}

Despite a presence of national policies in Honduras encouraging education for students with disabilities, there is a gap between policy and practice that negatively affects student learning in Honduras. The four commonly identified reasons for poor access and quality of learning for students with disabilities are social stigma and discrimination, lack of resources and infrastructure, inadequate pre-service training, and lack of knowledge among in-service teachers (Guadalupe, 2007; Viveros, 2004; Yasunaga, 2014). While not an exhaustive list, these four reasons help illuminate why students with disabilities generally do not receive an inclusive education in Honduras (Figure 1).

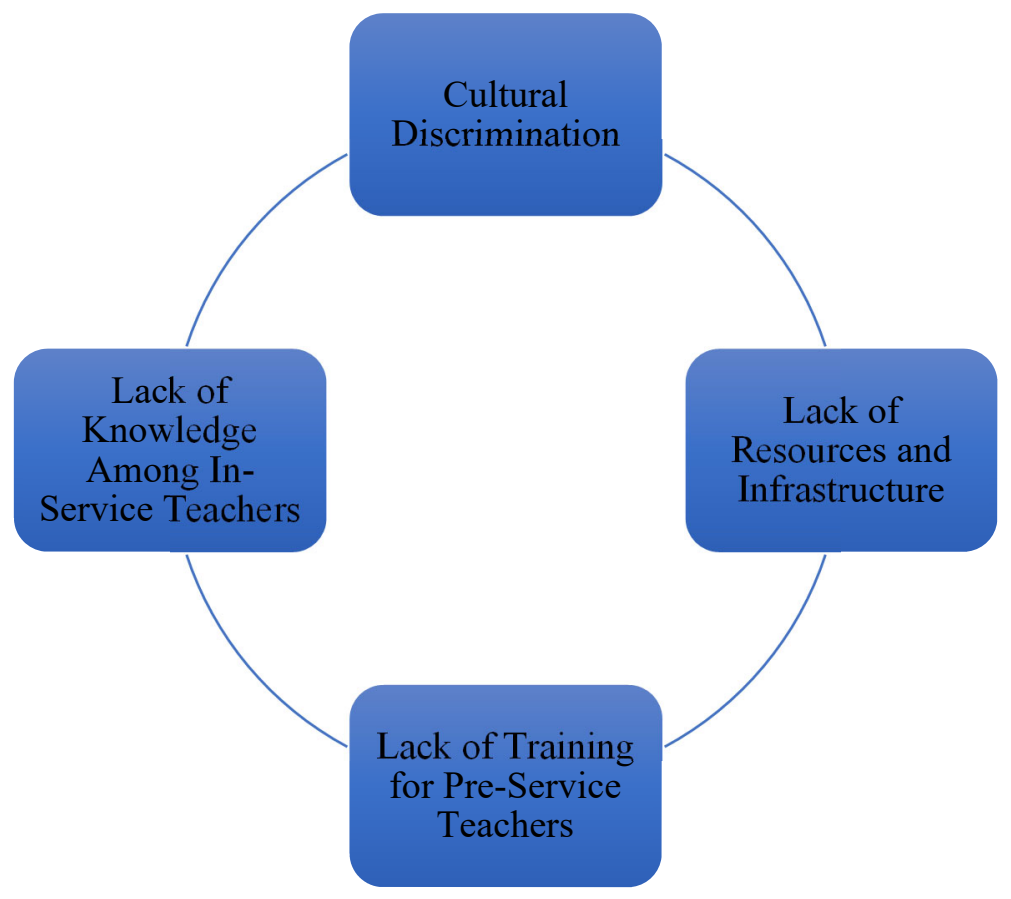

Figure 1. Reasons for the disconnect between policy and practice for students with disabilities.

Cultural discrimination. Amadio (2009) notes that there is an "existence of deeplyrooted negative social attitudes and discriminatory social practices" (p. 303) in general in Honduras that is corroborated in education settings by reports of students with disabilities often facing teasing and bullying by both their peers and teachers (National Federation of Organizations of Persons with Disabilities of Honduras, 2013; Schneider, 2017; Yasunaga, 
2014). In one study of students with disabilities in general education classrooms, researchers found that $14 \%$ reported feeling a lack of dignity at school and $16 \%$ faced discrimination and inequality (National Federation of Organizations of Persons with Disabilities of Honduras, 2013). The social stigma felt about disabilities is also experienced at home as noted by one study that found that some families kept their children with disabilities at home out of embarrassment (Japan International Cooperation Agency, 2002). Often, the media perpetuates these social notions by using pejorative terms and casting people with disabilities in the role of the victim (National Federation of Organizations of Persons with Disabilities of Honduras, 2013).

Lack of resources and infrastructure. Due to poor government spending and competing finances, there is a lack of resources and infrastructure for students with disabilities to access traditional school (Amadio, 2009; Richler, 2004). Specifically, Viveros (2004) notes the "lack of transportation ...equipment, furniture, learning materials, and access to school infrastructure" (p. 2). With only $4 \%$ of students with disabilities attending the special education centers, it is unclear what resources are being allocated to the majority of students with disabilities who attend general education schools. Indeed, anecdotal evidence indicates zero to minimal resources in rural areas earmarked for supporting students with disabilities in traditional general education classrooms (International Disability Rights Monitor, 2004). As spending theoretically reflects social priorities, the lack of spending for education for students with disabilities may be intertwined with the pervasive social stigma and discrimination towards people with disabilities.

Lack of training for pre-service teachers. The lack of training received by preservice general education teachers regarding how to appropriately work with students with disabilities is a third barrier to success. Although there is no official national policy on how much training general education pre-service teachers receive, research has shown that the commonly taught one course in teacher training programs is insufficient to prepare teachers for having students with disabilities in their classes (Guadalupe, 2007; International Disability Rights Monitor, 2004; Japan International Cooperation Agency, 2002; Schneider, 2017; Yasunaga, 2014). While there are degree programs specifically in special needs education, such as the five-year program at the National Pedagogical University, it is unclear how much effect graduates of these programs are having on the students with disabilities placed in the general education environment (International Disability Rights Monitor, 2004; Japan International Cooperation Agency, 2002).

Lack of knowledge among in-service teachers. The fourth reason for this disconnect between policy and practice is the lack of knowledge among in-service teachers about how to teach students with disabilities. Even if teachers receive instruction in their teacher training programs, research has shown that they are undertrained (Yasunaga, 2014). For example, many teachers do not know how to effectively differentiate their instruction and adapt the curriculum to suit the needs of their students with disabilities (Guadalupe, 2007; National Federation of Organizations of Persons with Disabilities of Honduras, 2013). Furthermore, professional development is largely missing for general education Honduran teachers (Yasunaga, 2014). Additionally, teachers report a lack of conditions conducive for collaboration with peers to develop best practices (Guadalupe, 2007).

\section{Professional Development for Education of Studies with Disabilities}

The high level of discrimination against people with disabilities is so ingrained in the Honduran culture that it is either directly or indirectly influencing the lack of funding, lack of pre-service training, and lack of knowledge among in-service teachers (Guadalupe, 2007; 
Viveros, 2004; Yasunaga, 2014). As in any educational system, the people responsible for appropriating the educational finances are products of the national culture; therefore, if the policy makers grew up in a society that views people with disabilities as inferior, those implicit cultural attitudes would be internalized and reflected in their decisions about allocating resources (Amadio, 2009). Similarly, if a society at large deemed students with disabilities to be inappropriate recipients of education due to their perceived inferiority, this discrimination would lead to a lack of instruction of how to effectively teach such students in pre-service teacher education programs (Amadio, 2009). A lack of financial resources directed towards education of students with disabilities may also affect the lack of focus on students with disabilities in pre-service teacher education; if these teacher education programs are working with a limited budget, they will have to prioritize the subjects taught to pre-service teachers, further marginalizing the time spent discussing appropriate education for students with disabilities (Guadalupe, 2007).

This interrelatedness of discrimination, lack of funding, and insufficient pre-service teacher training leads to a lack of knowledge for in-service teachers (Amadio, 2009; Yasunaga, 2014). The lack of PD for in-service teachers to try to fill this gap of knowledge is related to the lack of resources mentioned above in that there is not merely a lack of professional development about working with students with disabilities; there is a general lack of PD available on any topic due to absent funding (Umansky, 2005).

While all four reasons for a lack of effective education for students with disabilities in Honduras (cultural discrimination, lack of funding, lack of pre-service training, and lack of knowledge among in-service teachers) are connected, the lack of knowledge among in-service teacher surfaces as the most feasible to address via PD. Not only has PD has been shown to help teachers become more effective due to the fact that teachers are acknowledged to have a large impact on student outcomes in general, it has also been shown to be cost-effective and successful in poor Latin American communities, making it a practical approach for Honduras (Anderson, 2005; Tatto, 1998; Tucker, 2011).

Comparatively, while changing cultural attitudes is not easily done, it can be indirectly achieved by normalizing students with disabilities in the educational environment for younger generations, thus fostering a culture of tolerance and acceptance over time, hopefully leading to more funding as less discriminatory policy makers take office (Opertti \& Belalcázar, 2008). An additional argument for focusing on in-service instead of pre-service teachers is that if interventions only focused on pre-service teachers, they would not affect the current in-service teachers. However, if PD for in-service teachers could ultimately create a school environment that is inclusive of students with disabilities, future teachers might adapt to this accepting school culture and learn from more experienced in-service teachers to effectively work with students with disabilities (Knapp, 2003).

Theory of professional development. When determining why education for students with disabilities in practice is not living up to the ideals proclaimed in official policies, it is useful to consider Knapp's (2003) "Chain of Influences Connecting Policymakers' Actions with Professional and Student Learning" to identify points of entry to disrupt the ineffective system. Knapp theorized that PD can be a critical step in implementing national policies, such as those in Honduras geared towards providing an inclusive education for students with disabilities. This macro-level step is only connected to the micro-level student learning if teachers engage in the PD and change their knowledge, beliefs, and practices as a result (Knapp, 2003).

To better understand teacher knowledge change that could happen as part of PD, it is beneficial to consider Shulman's (1987) theories of different types of knowledge teachers 
have. He identified seven categories of teacher knowledge: content knowledge, general pedagogical knowledge, curriculum knowledge, pedagogical content knowledge, knowledge of learners, knowledge of educational contexts, and knowledge of the purpose of education (Shulman, 1987). PD can explicitly seek to change any number of these types of knowledge, and Knapp points to pedagogical knowledge as part of the process of using PD to influence student learning (Knapp, 2003).

When focusing on in-service teachers' learning by means of PD, Knapp's model is made more explicit in Desimone's framework to show the link between PD and student learning (Desimone, 2009). By providing PD consisting of the following five domains (content focus, active learning, coherence, duration, and collective participation), Desimone has shown that PD can not only increase teachers' knowledge and practice but also improve student achievement. Desimone (2011, p.69) notes that effective PD should include subject matter content along with pedagogical approaches to most effectively deliver the content, such as engagement in the form of providing and receiving feedback and analyzing student work instead of "passively sitting through lectures."

Furthermore, Desimone advocates for PD that lasts at least 20 hours per semester and PD that involves collective participation with teachers from their same school, level, and/or discipline to foster a dynamic learning community for teachers. While PD can still be effective if it is focused on only one of these characteristics, it is most effective when employing as many as possible (Kennedy, 2016).

In addition to the content and structure of PD, the type of PD has also been shown to be important (Kennedy, 2016; Opfer, 2016). On average in OECD countries, school embedded PD (such as professional learning communities, mentoring and coaching, classroom observation and feedback, and common assessment standards) has been more effective in increasing teacher self-efficacy, reported levels of preparedness, constructivist pedagogical beliefs, and satisfaction than non-school embedded PD (such as courses, workshops, conferences, and degree programs) (Opfer, 2016). Researchers have also found that the quality of the coach delivering the PD is vital to the effectiveness of the PD as teachers learn more from PD delivered from coaches who are more familiar with the subject matter (Kennedy, 2016).

Cultural relevance. When applying concepts and practices from one setting - such as the United States where research on PD and education for students with disabilities is plentiful - to Honduras, it is important that cultural context is taken into account to maximize the utility and effectiveness of the programs. In particular, the level of support given to teachers of students with disabilities in the United States is much higher than that in Honduras, so caution must be taken when applying research from the United States to Honduran contexts (Hallinger \& Leithwood, 1996). As Hallinger and Leithwood (1996) point out, "Culture...entails donning a new set of theoretical lenses" (p. 100) when applying international concepts and practices such as inclusive education in Honduras. Dimmock and Walker (2000) propose a framework for identifying cultural aspects inside and outside the classroom that affect student learning, specifically local community and social services, school culture, regional-level culture, and organizational culture. As is discussed below, the PD program evaluated addressed several of these nuances (Dimmock \& Walker, 2000).

Successful examples. With respect to how effective PD can help teachers best work with their students with disabilities, the United States serves as a fertile platform for research. As a result of the Individuals with Disabilities Education Act and No Child Left Behind, teachers in the US are struggling to learn appropriate ways to include students with disabilities in their classrooms as $80 \%$ of students with disabilities receive the majority of 
their instruction in the general education classroom. There has been a plethora of research done on the topic of inclusion to the extent that educators benefit from high quality PD to improve their teaching practice (Smith \& Tyler, 2011).

While it is generally acknowledged that PD can improve teachers' practice and mindset, there has been a line of research about PD geared specifically towards helping general education teachers work with students with disabilities. Researchers have found that PD can increase pedagogical knowledge of how to teach students with disabilities, make teachers more likely to collaborate with peers, and improve their attitudes towards inclusive education (Coombs-Richardson \& Mead, 2001; Knapp, 2003; Tatto, 1998; Waitoller \& Artiles, 2013). Furthermore, it has been shown that while any amount of PD improves teachers' perceived abilities to improve instruction to students with disabilities, teachers who receive more than eight hours of $\mathrm{PD}$ over a three-year time span show more than twice the increase compared to teachers with fewer than eight hours, which is significantly less than Desimone's recommended 20 hours over one semester (Desimone, 2011; Kosko \& Wilkins, 2009). One study showed that PD was a better predictor than experience when estimating teachers' perceived ability to work with students with disabilities (Kosko \& Wilkins, 2009).

\section{Professional Development Program Studied}

The PD program studied was conducted by a nonprofit development organization based in the Cangrejal River Valley in rural northern Honduras with a mission to improve the quality of life among marginalized Honduran communities by facilitating access to health care, education, and livable wages. This organization was run jointly by a board of directors from the United States and a board of directors in Honduras, comprised of local community stakeholders. In addition to development projects including clean water access, a women's economic cooperative, and literacy outreach, this organization conducted a program that I will refer to as El Proyecto (pseudonym). El Proyecto was a multifaceted approach to support children with disabilities with their healthcare and education by building capacity among stakeholders in the community to help the students reach their potential. Specifically, El Proyecto used a guiding theory of the interrelated importance of the roles of the teacher, parent, and education specialist in aiding each child's development. At the time of my evaluation, the program had been operating for three years and was funded by a grant from an European development organization. The overarching theme of the project was to provide individualized support to each student, mirroring the sentiment pervasive throughout inclusive education in the United States (Shade \& Stewart, 2001).

El Proyecto worked with 56 children from 45 families in 8 communities in the Cangrejal River Valley and delivered PD to the 15 teachers of these students located at public primary schools in the 8 communities via two methods. The first was by working with the 8 education specialists who were from the respective local communities that the nonprofit organization trained to work with students in the classroom weekly. By working with these

specialists, the teachers involved in the project learned about the nature of the disabilities and pedagogical techniques to most effectively teach students with disabilities. Specialists spent time in each teacher's classroom each week working directly with the children. They also met with the teachers individual weekly to discuss the students' progress and examine how the teachers could adjust their pedagogy to better meet the learning needs of individual students. Given the individualized needs of each child, the specialists suggested various teaching techniques to the teachers. To support the specialists, the nonprofit organizing the PD held weekly meetings with all 8 specialists where the specialists discussed difficulties they encountered and sought solutions. 
The second avenue of PD was whole group seminars where El Proyecto brought all 15 teachers together to learn from an education professional, typically a professor from the Universidad Pedagógica Nacional Francisco Morazán, the teacher training university located at the bottom of the river valley in La Ceiba, the third largest city in Honduras. While the teachers interacted with the specialists consistently twice a week, the number of whole group trainings fluctuated between zero to three per year based on resources.

\section{Research Question}

As El Proyecto sought to increase knowledge among general education teachers with respect to teaching students with disabilities, my evaluation was designed around the following research question: "Did teachers who participated in the professional development perceive it to be beneficial with respect to teaching students with disabilities? Why or why not?”

\section{Methods}

I conducted a small-scale qualitative program evaluation where I studied twelve of the fifteen teachers involved with the PD over the course of two months in 2016. In order to address my research question of teacher perception of the effectiveness of the PD, I conducted teacher interviews, classroom observations, and questionnaires. The research presented in this article was part of a larger program evaluation that I conducted that included perceptions for other stakeholders associated with the project, including the specialists and parents of students involved, that is outside the scope of this piece. My entire program evaluation had IRB approval prior to arriving in Honduras.

\section{Teacher Recruitment}

In order to answer the research question of how the PD program has influenced teachers' knowledge, I used stratified purposeful sampling where I stratified based on community (Creswell \& Poth, 2018). Given the high degree of insularity among the communities, the resulting unique cultures, and the tailoring of the PD program to the specific needs of individual teachers, it was important to capture the experiences of at least one teacher from each community to add depth and nuance to my study (Creswell \& Poth, 2018). Within each community, teachers volunteered based on availability.

\section{Participants and Setting}

The sample of teachers reported an average of 10.4 years of teaching experience, and $100 \%$ of them reported attending formal pre-service teacher training (which is required by the Ministry of Education to work in a public school yet, anecdotally, not always enforced). $75 \%$ of them had not received any type of formal training on how to work with students with disabilities. Of the three teachers who had received such training, two of them did so at a university, although it was unclear whether that had been part of their pre-service teacher training or an additional experience. The remaining teacher had attended a training session at a rehabilitation center.

The nature of the student and specialist distribution varied in response to the nature of the schools in each community. Of the eight communities, only one was large enough to have single-grade classes. While the majority of teachers taught two or three grades in the same class, there was one teacher who had all six grades of students at once. Thus, the number of students in El Proyecto ranged from one to four in each class. Likewise, some specialists had students spread across three classes in the school while others only worked with one or 
two classes. Accordingly, teachers reported an average number of 2.1 specialist classroom visits per week with an average of 7.3 hours per week the specialist spent in each classroom. In addition, teachers stated they met with their respective specialist an average of 1.1 times each week to discuss students. The teachers in the sample also reported attending an average of 1.7 group trainings (Table 1 ).

Table 1.

Demographic and descriptive information about teachers.

\begin{tabular}{ll} 
Descriptor & Statistic \\
\hline Number of teachers who participated in evaluation & 12 \\
Percent who received formal pre-service teacher training & $100 \%(N=12)$ \\
Percent who received formal training on working with students with & $25 \%(N=3)$ \\
disabilities & $10.4(5.6)$ \\
Average number of years teaching & $7.3(4.8)$ \\
Average number of years worked at current school & $2.2(0.8)$ \\
Average number of years involved in El Proyecto & $2.2(1.0)$ \\
Average number of students with disabilities in El Proyecto in classroom & $2.1(0.6)$ \\
Average number of visits per week specialist spent in classroom & $7.3(3.5)$ \\
Average number of hours per week specialist spent in classroom & $1.1(0.6)$ \\
Average number of meetings per week with specialist to discuss students & $1.7(1.3)$ \\
Average number of group training attended &
\end{tabular}

Note: Unless otherwise noted, standard deviations are in parenthesis.

\section{Procedures and Data Collection}

I collected all data in June and July 2016 in Honduras and spent two days in each community conducting as many classroom observations, interviews, and questionnaires as possible with the teachers who volunteered to participate. The Project Coordinator of El Proyecto transported me to each community and facilitated an introduction to each teacher. I personally carried out the interviews in Spanish.

Leaning on the concept of methodological triangulation to strengthen my study, I used three methods of data collection (Maxwell, 2013a; Patton, 2002). I conducted semistructured interviews with 12 teachers (at least one teacher per community) using an interview protocol I developed by combining the explicit research aims of the organization running El Proyecto (such as how often teachers were meeting with specialists) and results from similar PD programs conducted in the United States (such as a change in pedagogy towards students without disabilities) (Coombs-Richardson \& Mead, 2001). After I created the initial interview protocol, the Project Coordinator of El Proyecto reviewed and made appropriate edits for culturally responsive wording (Hallinger \& Leithwood, 1996). I conducted the interviews in Spanish by myself, and the average interview lasted 30 minutes. Participation was voluntary, and I kept the results confidential by using pseudonyms (Babbie, 2008). During the interview, I wrote down teachers' responses by hand in a journal and recorded the audio. I later transcribed the interviews electronically (Hesse-Biber, 2017; Ravitch \& Carl, 2016; Rubin \& Rubin, 2005; Wadsworth, 2011).

Due to limited timing with holidays, I conducted classroom observations of ten of the twelve teachers. Of these, I observed seven twice (once with and once without the specialist present) and three once (with the specialist present). On average, each observation lasted two hours. These ten teachers taught in seven of the eight communities. I used an observation 
protocol that focused on examining the spatial location of students with disabilities around the room, the pedagogical techniques teachers used when interacting with students with disabilities, and the extent to which interactions between the teachers and students with disabilities differed from those without disabilities (Coombs-Richardson \& Mead, 2001; Kosko \& Wilkins, 2009; Waitoller \& Artiles, 2013). I sat in an unobtrusive section of the classroom behind students and only moved when necessary so as to not draw extra attention to myself (Patton, 2002; Ravitch \& Carl, 2016). I took handwritten field notes in a journal (Saldaña \& Omasta, 2018). I did not engage with the students during observations due to IRB regulations.

My third method of data collection was questionnaires in Spanish given to twelve teachers in seven communities. Similar to the interviews, the questionnaires were edited for culturally appropriate language by the Project Coordinator prior to distribution (Hallinger \& Leithwood, 1996). Participation was voluntary, and results were kept confidential using pseudonyms (Babbie, 2008). The questionnaires took approximately 20 minutes to complete. After questionnaire completion, I coded the responses electronically for further analysis. Similar to the interview questions, the questionnaires items were a mixture of questions from the organization and results I theorized about from my prior literature review.

\section{Coding Procedures}

For my coding of the open-ended questions in my questionnaires and interviews, I used provisional and hypothesis coding to analyze what teachers have learned and how their teaching has changed as a result of the professional development (Saldaña, 2016). I chose to employ these coding schemes because on my theory that teachers would learn more about the disabilities their students had and how to more effectively teach those students, based on prior research conducted using similar PD interventions (Coombs-Richardson \& Mead, 2001; Kosko \& Wilkins, 2009; Waitoller \& Artiles, 2013).

Given my focus on teacher knowledge, I based my coding on the types of teacher knowledge as discussed by Shulman with its seminal relevance in the teacher education literature (Shulman, 1987). I began by reading through my data responses with the seven types of knowledge that Shulman discusses and then eliminated two categories as they did not pertain to my research question. I finalized my coding scheme with the following five codes:

- General pedagogical knowledge (Pedagogy of how to teach students with disabilities that applies to multiple contents)

- Pedagogical content knowledge (Pedagogy of how to teach students with disabilities that is content-specific)

- Knowledge of learners and their characteristics (Knowledge of disabilities)

- Knowledge of educational contexts (Knowledge of broader educational system)

- Knowledge of educational values (Knowledge of equity and inclusion of students with disabilities)

For coding my classroom observations, I looked for examples of teaching practice that either seemed to be purposefully inclusive or exclusive of students with disabilities according to previous research. Examples included providing students with extra time on assessments, writing key words on the board when discussing them orally, giving students extra help in drawing geometric figures, providing verbal encouragement, and seating students with disabilities in the front versus back of the room (Coombs-Richardson \& Mead, 2001; Kosko \& Wilkins, 2009; Waitoller \& Artiles, 2013). After initially coding my observations, I 
returned to my notes to specifically look for instances of teachers employing pedagogical practices that they told me during their interviews they learned from their PD.

\section{Results}

\section{Change in Teacher Knowledge}

\section{Students with disabilities.}

Using the teacher knowledge profiles discussed in Shulman (1987), teachers most commonly reported knowledge gains in general pedagogical knowledge that applied to multiple content areas. Teachers also reported gains in pedagogical content knowledge, knowledge of learners and their characteristics, knowledge of educational contexts, and knowledge of educational contexts for students with disabilities (Shulman, 1987). Examples of knowledge teachers reported that I verified through observation include providing extra time on assessments, writing key words on the board while discussing their orally, and using math manipulatives. These changes in knowledge are positive indicators of the effectiveness of the PD in changing the lack of knowledge among in-service Honduran teachers about how to work with students with disabilities.

In terms of knowledge change, $100 \%$ of teachers reported learning either "Somewhat" or "Very Much" about disabilities as a result of El Proyecto (Figure 2). As a result of knowledge gained, 11 of 12 teachers reported a change in pedagogy for their students with disabilities as a result of what they learned from the project, either through the specialists or the group trainings provided by the organization.

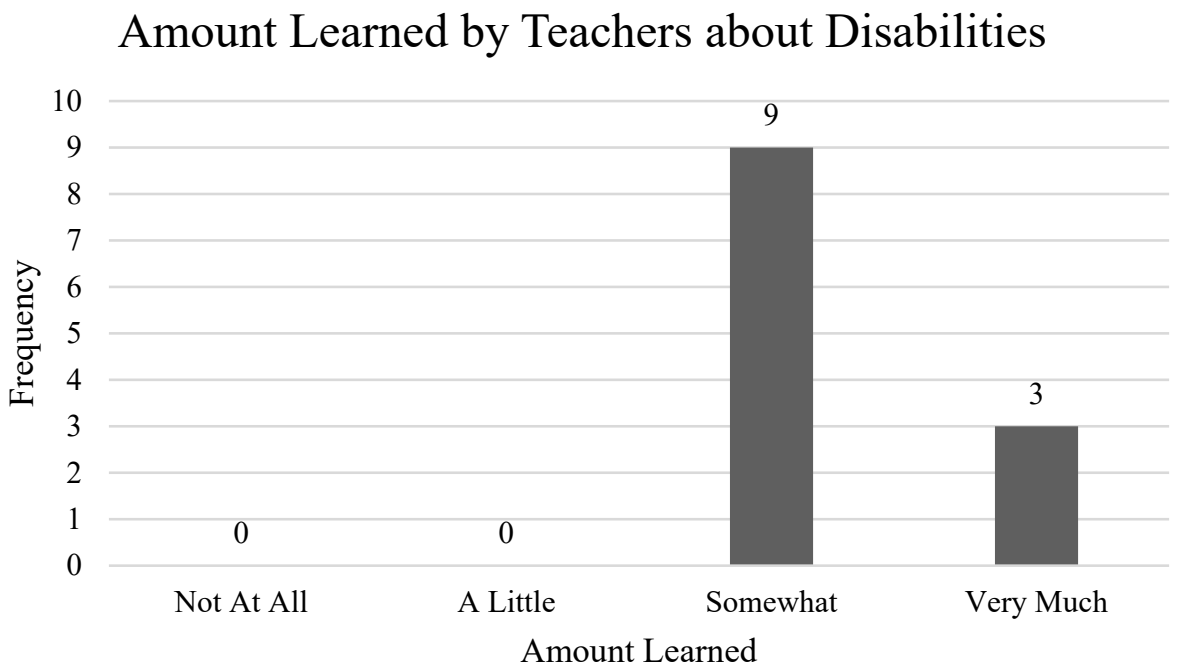

Figure 2. Amount learned about disabilities, as reported by teachers.

When asked about specific examples of knowledge acquired during interviews, the teachers most commonly answered about general pedagogical knowledge that could translate to multiple content areas:

- "Helping a student with body tremors how to use a ruler to draw a line instead of drawing it freehand"

- "Try to teach things that are more interesting to students" [ such as incorporating sports into lessons]

- "Give children more time" [on assessments] 
- "Learn to always encourage students with special needs"

- "Using more teaching materials" [such as math manipulatives]

- "Dedicate a bit more time to them, as much as the situation will allow"

For all of the responses above, I observed teachers using the articulated teaching techniques during my classroom observations (Patton, 2002). Additionally, some teachers also expressed gaining pedagogical content knowledge for Math and Spanish for their students with disabilities including, "Working with materials with them [such as] cards with numbers in math, cards with figures in Spanish." During one classroom observation, I observed an example of pedagogical content knowledge in action when one teacher used bottle caps for tactile manipulatives to allow students with disabilities to practice multiplication. including:

Two teachers noted explicitly gaining knowledge of learners and their characteristics,

- “...dysgraphia, dyslexia, and dyscalculia”

- “...learned physical exercises to help the student with mobility problems”

One teacher demonstrated gaining knowledge of educational values for students with disabilities by stating, "... before, [the school] would basically throw out a student with special needs but now [I] know how to work with these students and welcome them."

When teachers were asked about difficulties they face in teaching students with disabilities, multiple teachers reported knowledge of educational contexts that negatively affected students with disabilities, including:

- "The curriculum is too focused on memorization instead of learning"

- "Have to change mindset of people here"

- "There are 6 grades in one class...do not have the time to give [students with disabilities] the attention they need"

- "Dividing attention between students" [during class time]

In addition to helping teachers better understand the academic needs of their students with disabilities, teachers reported that El Proyecto helped them to better understand their students' social interactions and, to a lesser extent, their health needs. Overall, 11 of 12 teachers reported an increase in comfort level working with students with disabilities as a result of participating in the $\mathrm{PD}$.

\section{Reason for Knowledge Change}

When I asked teachers about what aspect of the PD was more successful for them for improving their teaching, the majority of teachers noted the role of the specialists. In particular, several teachers noted the value of the specialists' relationships with students, their help in the classroom, and their support with parents. While all the teachers found the specialists' classroom visits useful, they reported the most helpful part of the classroom visits was the work the specialists do with the students as opposed to the time spent with the teachers (Figure 7). This was reflected in the fact that almost as many teachers reported using the suggestions received from the specialists "A Bit" as "Often" (Figure 3). When asked about the most useful information received from specialists, teachers reported:

- "Information about the students' disabilities"

- "Updates on how the students were progressing" 
- "Techniques for modifying classroom instruction and assignments for students, particularly the reminder to have patience"

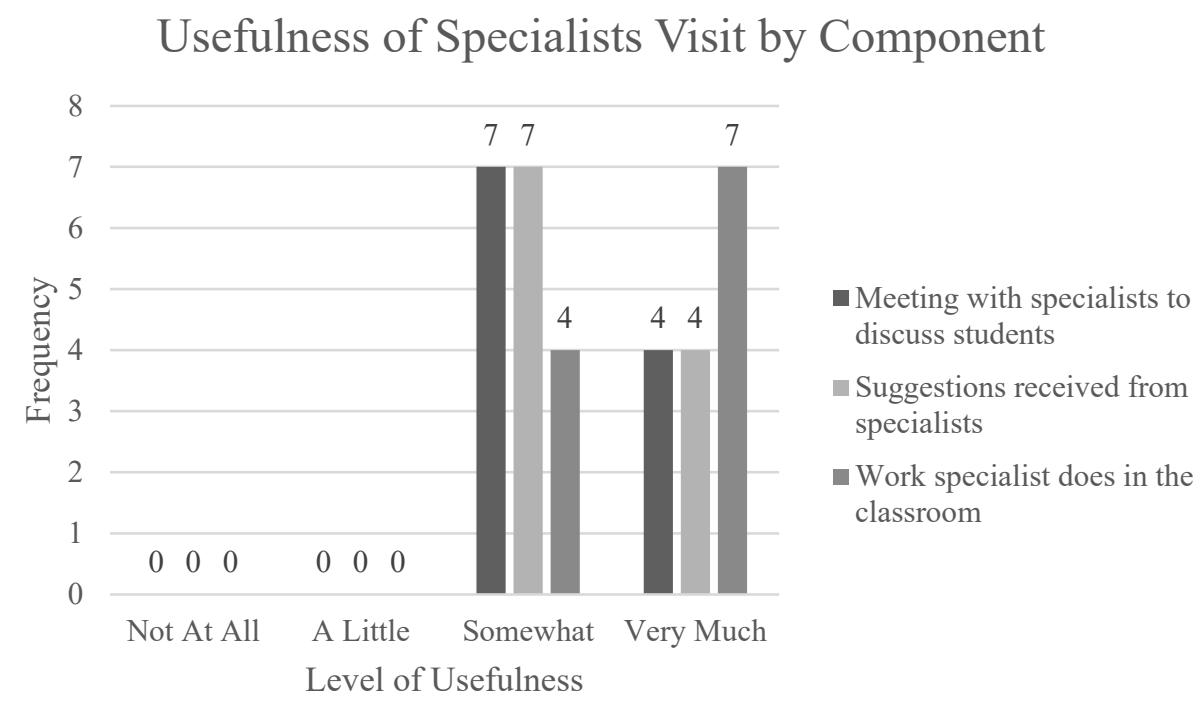

Figure 3. Usefulness of types of interactions with specialists, as reported by teachers.

For the second part of the PD intervention - the approximately semi-annual group trainings - teachers reported finding these trainings helpful for improving their teaching practice. When asked about the most helpful information received in the group trainings, two teachers noted the occasion where students with disabilities were brought in to help demonstrate appropriate pedagogical techniques. However, while the teachers noted that while they found the group trainings useful, they found the interactions with the specialists more effective for improving their teaching practice (Figure 4).

\section{Teacher Network}

As a result of participating in El Proyecto, 10 of 12 teachers reported sharing what they had learned with another teacher, either at their school or at a different school. 9 of 10 noted that El Proyecto has given them access to a network of teachers who also have received training on working with students with disabilities. Of these 9 teachers, $100 \%$ felt that this network was either "Somewhat" or "Very Much" useful. Furthermore, $100 \%$ of all 12 teachers surveyed reported that they would like more opportunities to meet with other teachers who have had training for students with disabilities.

\section{Discussion}

Teachers reported feeling that the PD was beneficial because it improved their knowledge in teaching students with disabilities. These changes in teacher knowledge and practice were important given that only three teachers reported having previous training on how to work with students with disabilities despite every teacher having gone through a formal preservice teacher training program. This aligned with previous reach on the lack of training on disabilities in Honduran teacher training programs (Guadalupe, 2007; International Disability Rights Monitor, 2004; Japan International Cooperation Agency, 2002; Yasunaga, 2014). In addition to improving their pedagogy for students with disabilities, 
many teachers reported learning information from the PD that bettered their teaching with students without disabilities, a secondary benefit that improves the quality of learning for all students (Guadalupe, 2007; National Federation of Organizations of Persons with Disabilities of Honduras, 2013; Yasunaga, 2014).

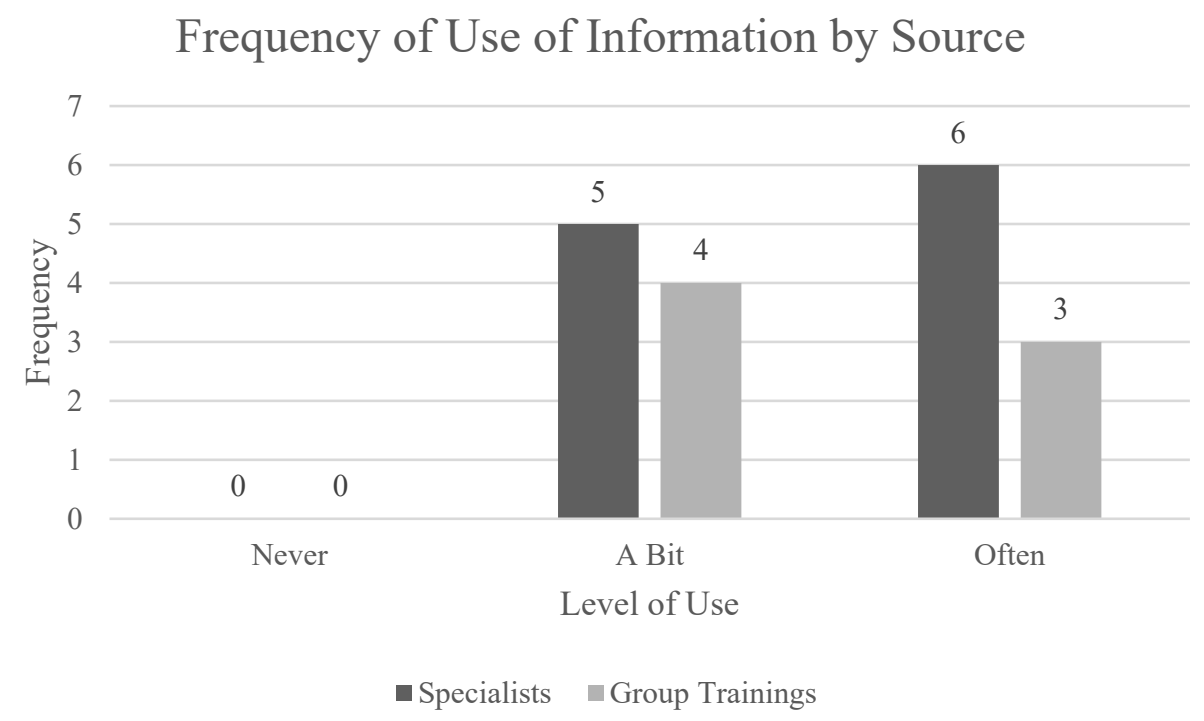

Figure 4. How often teachers used information from aspects of PD, as reported by teachers.

As teachers learn more about disabilities and how to best teach students with disabilities, many reported an increase sense of ease in working with and a more accepting attitude towards such students. This was an indication of a shift in the pervasive cultural discrimination against people with disabilities in Honduras (Amadio, 2009; Japan International Cooperation Agency, 2002; National Federation of Organizations of Persons with Disabilities of Honduras, 2013; Yasunaga, 2014). When asked about why their knowledge had changed, teachers reported valuing their interactions with the specialists, the relationship the specialists had formed with the students, and the teacher network the PD provided, mirroring similar studies conducted in the United States (Coombs-Richardson \& Mead, 2001; Waitoller \& Artiles, 2013).

As teacher reported changes in knowledge about how to teach students with disabilities and their attitudes towards the place of those students in general education classes, I found that the PD program affected positive change in two of the four reasons I identified for the gap between policy and practice (Figure 1). The positive outcomes in teacher cultural beliefs, knowledge, and pedagogical practice are encouraging both in the effectiveness of this program and its use as an example for similar regions in Latin America.

\section{Limitations}

My positionality as a former teacher who was trained in how to work with students with disabilities during teacher education influenced my perceptions of what I did and did not notice during classroom observations (Peshkin, 1988). Also, my status as an outside evaluator with previous program evaluation experience may have allowed me to notice things that insiders may not have and ask questions that otherwise may not have been asked. Conversely, my lack of insider status may have prevented participants from being as forthcoming as they would have otherwise or asking questions that seemed irrelevant (Wadsworth, 2011). 
Another aspect as my status as an outsider is that I was not steeped in the educational and social culture particular to the Cangrejal River Valley in a manner that would have enabled me to understand nuances during my interviews and classroom observations. Although I had studied the Honduran education system prior to conducting my research and spend time in other Central American educational contexts, there is no substitute for experiencing a culture in person. While this had implications for the validity of my study if I missed or misinterpreted something, it also affected my positionality because I may have viewed an interaction or interpreted a response according to my experiences with the U.S. educational system. I am particularly concerned about this in regard to the classroom observations. My protocol dictated that I observe teacher interactions with students, and it is possible that I only noticed behaviors that I was taught during my teacher education program to be best practice (such as providing extra time on tests).

Additionally, my status as a U.S. citizen might be salient to my work given the historical nature of political intervention and extractive economic policies in Honduras and Central America as a whole. As a representative of a nation who may have indirectly contributed to the marginalization of the population studied, my presence could have been a tangible reminder of these historical and political events and their impacts (BarclayMcLaughlin \& Hatch, 2005).

To help prevent against biased interview responses and my interpretations of it caused by some of these concerns, I employed triangulation, culturally relevant wording, and respondent validation (Hallinger \& Leithwood, 1996; Maxwell, 2013b; Patton, 2002). Additionally, another limitation of my study was that all data collection was conducted in Spanish, which is not my native language. To increase the internal validity of my interviews, I recorded them when given written permission in order to transcribe later and printed out my interview questions in Spanish if a teacher had trouble understanding my accent (Maxwell, 2013b).

\section{Conclusion}

Despite national policies advocating for education for students with disabilities in Honduras, students with disabilities have significantly worse educational outcomes as compared to their counterparts. Two of the reasons for this are a lack of knowledge among in-service general education teachers about how to teach students with disabilities and pervasive cultural discrimination. In an attempt to change this, an organization in rural Honduras operated a professional development program that provided training to fifteen general education teachers through weekly interactions with specialists from the local communities. These specialists worked with the teachers on increasing their knowledge of the students' disabilities and improving their pedagogy with these students. Teachers reported changes in their attitudes towards the inclusiveness of the education system, knowledge of disabilities, teaching practices with students with disabilities, and ease in working with students with disabilities. This program provided insight into successful models that can be used in similar communities in Latin America to improve education for students with disabilities.

\section{Acknowledgements}

This research was conducted using a Tinker Research Grant funded through the Center for Latin American Studies at Vanderbilt University. Research was approved by the Vanderbilt University Institutional Review Board, IRB \#160608. I would like to thank the staff, 
teachers, and specialists who ran the program and worked in the schools I studied in Honduras for their invaluable hospitality, insight, and efforts in helping me complete this research as well as their commitment to improving the educational opportunities for students with disabilities. Additionally, I would like to thank Drs. Carolyn Heinrich, Xiu Cravens, Brian Heuser, Avery Dicken de Girón, Ted Fischer, Leah Bricker, and Mrs. Alma PazSanmiguel for their help with and encouragement of this work. I also thank the anonymous referees for guiding comments.

\section{References}

Amadio, M. (2009). Inclusive education in Latin America and the Caribbean: Exploratory analysis of the national reports presented at the 2008 International Conference on Education. Prospects, 39(3), 293-305. https://doi.org/10.1007/s $11125-009-91$ 14-1

Anderson, J. B. (2005). Improving Latin America's school quality: Which special interventions work? Comparative Education Review, 49(2), 205-229. https://doi.org/130.126.32.13

Babbie, E. (2008). The basics of social research (4th ed.). Belmont, CA: Thomson Wadsworth.

Barclay-McLaughlin, G., \& Hatch, J. A. (2005). Studying across race: A conversation about the place of difference in qualitative research. Contemporary Issues in Early Childhood, 6(3), 216-232. https://doi.org/10.2304/ciec.2005.6.3.3

Connor, D. J., \& Ferri, B. A. (2007). The conflict within: Resistance to inclusion and other paradoxes in special education. Disability Eீ Society, 22(1), 63-77. https://doi.org/10.1080/09687590601056717

Coombs-Richardson, R., \& Mead, J. (2001). Supporting general educators' inclusive practices. Teacher Education and Special Education, 24(4), 383-390. https://doi.org/10.1177/088840640102400412

Creswell, J. W., \& Poth, C. N. (2018). Data collection. In Qualitative inquiry and research design: Chosing among five approaches (4th ed., pp. 147-180). Thousand Oaks, CA: Sage.

Desimone, L. (2009). Improving impact studies of teachers' professional development: Toward better conceptualizations and measures. Educational Researcher, 38(3), 181199. https://doi.org/10.3102/0013189X08331140

Desimone, L. (2011). A primer on effective professional development. Kappan, 92(6), 68-71. https://doi.org/10.1177/003172171109200616

Dimmock, C., \& Walker, A. (2000). Developing comparative and international educational leadership and management: A cross-cultural model. School Leadership \& Management, 20(2), 143-160. https://doi.org/10.1080/13632430050011399

Guadalupe, C. (2007). The state of education in Latin America and the Caribbean: Guaranteeing quality education for all. https://doi.org/10.1 146/annurev.anthro.30.1.227

Hallinger, P., \& Leithwood, K. (1996). Culture and educational administration: A case of finding out what you don't know you don't know. Journal of Educational Administration, 34(5), 98-116.

Hesse-Biber, S. N. (2017). In-depth interviewing. In The practice of qualitative research (3rd ed., pp. 104-147). Thousand Oaks, CA: Sage.

Hesse-Biber, S. N., \& Leavy, P. L. (2017). Designing qualitative approaches to research. The Practice of Qualitative Research (3rd ed.). Thousand Oaks, CA: Sage.

International Disability Rights Monitor. (2004). International disability rights monitor: Regional report of the Americas. Retrieved from http://www.idrmnet.org/content.cfm?id $=5 \mathrm{E} 5 \mathrm{~A} 75 \& \mathrm{~m}=3$ 
Japan International Cooperation Agency. (2002). Country profile on disability: Republic of Honduras. Retrieved from http://gwweb.jica.go.jp/km/FSubject0601.nsf/50e70e491615c34a492571c7002a98 2d/92d73365c37a365b492572920024f414/\$FILE/Honduras(2002).pdf

Kennedy, M. M. (2016). How does professional development improve teaching? Review of Educational Research, 86(4), 1-36. https://doi.org/10.3102/0034654315626800

Knapp, M. S. (2003). Professional development as a policy pathway. Review of Research in Education, 27, 109-157.

Kosko, K. W., \& Wilkins, J. L. M. (2009). General educators' in-service training and their self-perceived ability to adapt instruction for students with IEPs. The Professional Educator, 33(2), 1-10.

Maxwell, J. A. (2013a). Methods: What will you actually do? In Qualitative research design: An interactive approach (3rd ed., pp. 87-119). Los Angeles, CA: Sage.

Maxwell, J. A. (2013b). Validity: How might you be wrong? In Qualitative research design: An interactive approach (3rd ed., pp. 121-138). Los Angeles, CA: Sage.

National Federation of Organizations of Persons with Disabilities of Honduras. (2013). Monitoring of human rights of persons with disabilities: A comprehensive analysis of compliance and breach of fundamental rights in Honduras. Retrieved from http://drpi.research.yorku.ca/wpcontent/uploads/2014/12/DRPIHondurasRepEn.pdf

Opertti, R., \& Belalcázar, C. (2008). Trends in inclusive education at regional and interregional levels: Issues and challenges. Prospects, 38, 113-135. https://doi.org/10.1007/s1 1125-008-9062-1

Opfer, D. (2016). Conditions and practices associated with teacher professional development and Its impact on instruction in TALIS 2013 (OECD Education Working Papers No. 138). Paris. https://doi.org/http://dx.doi.org/10.1787/5jlss4rolrg5-en

Organization of American States. (2011). Signatories and ratifications: A-65 Inter American convention on the elimination on all forms of discrimination against persons with disabilitie. Retrieved January 1, 2016, from http://www.oas.org/juridico/english/sigs/a-65.html

Oxford Poverty and Human Development Initiative. (2016). Honduras Country Briefing. Retrieved from www.ophi.org.uk/multidimensional-poverty-index/mpi-countrybriefings/

Patton, M. Q. (2002). Qualitative research and evaluation methods (2nd ed.). Thousand Oaks, CA: Sage.

Peshkin, A. (1988). In search of subjectivity one's own. Educational Researcher, 17(7), 17-21. https://doi.org/10.3102/0013189X017007017

Ravitch, S. M., \& Carl, N. M. (2016). Qualitative research: Bridging the conceptual, theoretical, and methodological. Thousand Oaks, CA: SAGE Publishing.

Republica de Honduras: Secretaría de Educación. (2008). National report on the development of Honduras education. Retrieved from http://www.ibe.unesco.org/National_Reports/ICE_2008/honduras_NRo8.pdf

Richler, D. (2004). 2005 EF A monitoring report - Commissioned study: Quality education for persons with disabilities. Retrieved from http://unesdoc.unesco.org/images/O014/001466/146694e.pdf

Rubin, H. J., \& Rubin, I. S. (2005). Qualitative interviewing: The art of hearing data (2nd ed.). Thousand Oaks, CA: SAGE Publishing.

Saldaña, J. (2016). First cycle coding methods. In The coding manual for qualitative researchers 
(pp. 67-210). Thousand Oaks, CA: Sage. https://doi.org/10.1016/B978-04445 19542/50009-6

Saldaña, J., \& Omasta, M. (2018). Analyzing field sites. In Qualitative research: Analyzing life (pp. 29-62). Thousand Oaks, CA: Sage.

Schneider, C. (2017). Teachers' perceptions of disabilities on the ssland of Roatán, Honduras. Disability, CBR and Inclusive Development, 28(2), 5-22. https://doi.org/10.5463/dcid.v28i2.573

Shade, R. A., \& Stewart, R. (2001). General education and special education preservice teachers' attitudes toward inclusion. Preventing School Failure, 46(1), 37-41. https://doi.org/10.1080/10459880109603342

Shulman, L. (1987). Knowledge and teaching: Foundations of the new reform. Harvard Educational Review, 57(1), 1-23. https://doi.org/10.17763/haer.57.1.j463w79r56455411

Shulman, L. (1997). Disciplines of inquiry in education: A new overview. In R. M. Jaeger (Ed.), Contemporary methods for research in education (2nd ed., pp. 3-29). Washington, DC: American Educational Research Association.

Smith, D. D., \& Tyler, N. C. (2011). Effective inclusive education: Equipping education professionals with necessary skills and knowledge. Prospects, 41, 323-339. https://doi.org/10.1007/s $11125-011-9207-5$

Solís, M. A., \& Godoy, G. E. M. (2010). Equity problem in the Honduran educative system (Vol. 3). Retrieved from https://dialnet.unirioja.es/servlet/articulo?codigo $=3690495$

Tatto, M. (1998). The influce of teacher education on teachers' beliefs about purposes of education, roles, and practice. Journal of Teacher Education, 49(1), 66-77.

Tucker, M. S. (2011). Standing on the shoulders of giants: An American agenda for education reform. https://doi.org/10.1017/CBO9781107415324.004

Umansky, I. (2005). A literature review of teacher quality and incentives. In E. Vegas (Ed.), Incentives to improve teaching: Lessons from Latin America (pp. 21-62). World Bank Publications.

UN. (2017). Sustainable Development Goal 4. Retrieved October 5, 2017, from https://sustainabledevelopment.un.org/sdg4

UNDP. (2016). Human development for everyone: Honduras. Retrieved from http://hdr.undp.org/sites/all/themes/hdr_theme/country-notes/HND.pdf

UNESCO International Bureau of Education. (2010). World data on education: Honduras, 7 th edition. Retrieved from http://www.ibe.unesco.org/

UNESCO UIS. (2017). UIS.Stat: Education. Retrieved from http://data.uis.unesco.org/

UNICEF. (2011). Honduras: Country programme document 2012-2016. Retrieved from https://www.unicef.org/about/execboard/files/Honduras_final_approved_20122016_English_20_Oct_2011.pdf

Viveros, A. (2004). Latin America: World Bank calls for action on disability and poverty, as world celebrated International Day of Disabled Persons on Friday. Normans Media Limited.

Wadsworth, Y. (2011). Everyday evaluation on the run: The user-friendly introductory guide to effective evaluation (3rd ed.). Walnut Creek, CA: Left Coast Press, Inc.

Waitoller, F. R., \& Artiles, A. J. (2013). A decade of professional development research for inclusive education: A critical review and notes for a research program. Review of Educational Research, 83(3), 319-356. https://doi.org/10.3102/0034654313483905

Yasunaga, M. (2014). Non-formal education as a means to meet learning needs of out-of-school children and adolescents. Retrieved from http://allinschool.org/wp- 
content/uploads/2015/01/OOSC-2014-Non-formal-education-for-OOSC-final.pdf Zigmond, N., Kloo, A., \& Volonino, V. (2009). What, where, and how? Special education in the climate of full inclusion. Exceptionality, 17(4), 189-204.

https://doi.org/10.1080/09362830903231986

\section{About the Author}

Amanda Ketner Weissman is a doctoral candidate at the University of Michigan receiving a Ph.D. in Quantitative Research Methods of Education and a M.A. in Statistics. She specializes in program evaluation, causal inference, and data science of education policy with a particular emphasis on domestic and international programs targeting marginalized student populations. However, this work was completed when she was earning her M.Ed. in International Education Policy and Management at Vanderbilt University focusing on education in Latin America. 